\title{
CONTRIBUIÇÕES DO PROGRAMA RESIDÊNCIA PEDAGÓGICA À FORMAÇÃO INICIAL DE FUTUROS PROFESSORES DE LÍNGUAS: ASPECTOS DA PARCERIA COLABORATIVA
}

\author{
Caroline Carnielli BIAZOLLI \\ Universidade Federal de São Carlos +UFSCar \\ São Carlos, SP - Brasil \\ caroline.biazolli@ufscar.br \\ https://orcid.org/0000-0002-8578-8102 \\ Isadora Valencise GREGOLIN \\ Universidade Federal de São Carlos +UFSCar \\ São Carlos, SP-Brasil \\ isadora.gregolin@ufscar.br \\ https://orcid.org/0000-0002-9345-3126 \\ Joceli Catarina STASSI-SÉ \\ Universidade Federal de São Carlos +UFSCar \\ São Carlos, SP-Brasil \\ jocelistassise@ufscar.br
} https://orcid.org/0000-0001-7847-4247

RESUMO: Este artigo busca analisar as contribuições do Programa Residência Pedagógica (PRP/CAPES) à formação de licenciandos em Letras de uma instituição pública do interior paulista, bem como problematizar aspectos da parceria colaborativa entre universidade e escolas que têm fomentado discussões sobre a reformulação curricular do referido curso. Para isso, discutimos as concepções e princípios que embasam a formação docente inicial nessa instituição, apresentamos a proposta da primeira edição do programa e os desafios impostos pela pandemia para o desenvolvimento da segunda edição. Concluímos que a nova configuração dos estágios remotos evidenciou a importância de momentos presenciais para a constituição de identidades docentes. Ao mesmo tempo, favoreceu o engajamento dos estagiários com o próprio processo de aprendizado da docência e possibilitou uma maior interação com os preceptores, consolidando a parceria que vem sendo construída na última década.

PALAVRAS-CHAVE: Programa Residência Pedagógica. Parceria colaborativa. Formação inicial. Professores de línguas. 


\title{
CONTRIBUTIONS OF PROGRAMA RESIDÊNCIA PEDAGÓGICA TO THE INITIAL TRAINING OF FUTURE LANGUAGE TEACHERS: ASPECTS OF COLLABORATIVE PARTNERSHIP
}

\begin{abstract}
Thisarticleseekstoanalyzethecontributionsof Programa Residência Pedagógica totheinitial training of future languageteachersof a publicinstitution in São Paulo/Brazil. In addition, it aimsto problematize aspectsofthecollaborativepartnershipbetweenuniversitiesandschoolsthathavefostereddiscussionsonthe curricular reformulationofthereferredcourse. Toreachthisgoal, thepaperdiscussestheconceptionsandprinciplesthatsupporttheinitial training of future languageteachers in thisinstitutionand it presentstheproposalofthefirsteditionoftheProgram as wellthechallengesimposedbythepandemic for thedevelopmentofthesecondedition. In conclusion, the online configurationofthesupervisedinternshiphighlightedtheimportanceofpresencemoments for theconstitutionofteachingidentities. At thesame time, it allowedtheengagementofthe future languageteacherswiththeirlearningprocess, and it allowedgreaterinteractionwiththepreceptors, consolidatingthepartnershipthathasbeenbuilt in thelastdecade.
\end{abstract}

KEYWORDS: Programa Residência Pedagógica. CollaborativePartnership. Initial training. Languageteachers.

\section{CONTRIBUCIONES DEL PROGRAMA RESIDÊNCIA PEDAGÓGICA A LA FORMACIÓN DE FUTUROS PROFESORES DE LENGUAS: ASPECTOS DE LA COLABORACIÓN ENTRE UNIVERSIDAD Y ESCUELAS}

RESUMEN: Este artículo presenta lascontribucionesdel Programa Residência Pedagógica (PRP/CAPES) a laformación de alumnosdel curso de Letras de una institución pública de São Paulo/Brasil. Propone, además, planteamientos acerca de algunos de los aspectos de lacolaboración entre universidad y escuelas que contribuyen para lapropuesta de reformulación curricular del referido curso. Para ello, se discutenlasconcepciones y principios que basanlaformación docente inicial de lainstitución, se presenta lapropuesta de laprimeraedicióndel Programa Residência Pedagógica y eldesafíoimpuesto por la pandemia para eldesarrollo de la segunda edición. Concluímos que lanuevaconfiguración de laspasantías a distanciahapuesto de relievelaimportancia de los momentos presenciales para laconstitución de identidades docentes. Sin embargo, ha favorecido elcompromiso de lospasantesconsupropioproceso de aprendizaje de ladocencia y una mayoraproximación e interacciónconlos preceptores, consolidando lacolaboración entre universidad y escuelas que se está construyendoenel último decenio.

PALABRAS-CLAVE: Programa Residência Pedagógica. Colaboración. Formación inicial. Profesores de lenguas. 


\section{Introdução}

O debate sobre a articulação entre teorias e práticas na formação de professores (inicial ou continuada) não é recente (SANTOS, 1992; GAUTHIER et al., 1998; IMBERNÓN, 2000; TARDIF, 2000, 2002; ROMANOWSKI; MARTINS, 2010; dentre outros estudos). Nos cursos de licenciatura em geral, o grande esforço deve se centrar na manutenção de uma interface teórico-prática em todas as disciplinas ministradas. No caso das licenciaturas em Letras, em princípio, essa interface significa proporcionar aos futuros professores de línguas ampla formação, na qual se articulem conhecimentos específicos dos fatos das línguas - linguísticos e literários - com o efetivo preparo pedagógico-didático para abordá-los no interior das escolas de educação básica.

Baseando-nos na realidade de um curso de licenciatura em Letras de uma instituição de ensino superior (IES) pública do interior de São Paulo, identificamos momentos diferentes e oportunos na formação desses futuros professores em que eles podem experienciar práticas docentes no contexto de ensino e de aprendizagem de línguas. São eles, por exemplo, o contato ainda na primeira metade do curso com o cotidiano de escolas públicas, por meio do Programa Institucional de Bolsas de Iniciação à Docência (PIBID/CAPES)1 da instituição, e a realização dos estágios curriculares supervisionados obrigatórios nos anos finais do curso.

Neste artigo, interessa-nos o acontecimento dos estágios, que, no curso em pauta, a partir de 2018, têm ocorrido sobretudo por intermédio do vínculo entre as disciplinas de estágio e o Programa Residência Pedagógica (PRP/CAPES), uma vez que objetivamos avaliar as contribuições desse programa para a formação de licenciandos em Letras dessa IES pública e, ainda, problematizar aspectos da parceria colaborativa (FOERSTE, 2004) entre universidade e escolas que têm fomentado discussões sobre a reformulação curricular do referido curso.

O PRP, com duração de dezoito meses, "tem por objetivo induzir o aperfeiçoamento da formação prática nos cursos de licenciatura, promovendo a imersão do licenciando na escola de educação básica, a partir da segunda metade de seu curso" (CAPES, 2018, s/p, online). Na IES de que tratamos, seguindo os projetos institucionais submetidos à CAPES nos dois editais do PRP lançados até então, consta que o programa deve abarcar toda a carga horária das disciplinas de estágio que são oferecidas para os cursos de licenciatura e, para além disso, computar outras horas como carga complementar, totalizando, ao término desses dezoito meses, 576 horas de atividades feitas. Com essa finalidade, todas as iniciativas desenvolvidas possibilitam ao licenciando vivenciar "o ato docente como fenômeno concreto" (SAVIANI, 2009, p. 151) ou, como dito por Nóvoa (2009) e retomado na próxima seção, o "exercício da profissão".

Para alcançarmos os objetivos aqui propostos, este artigo está dividido em três partes, além das considerações finais em que arrematamos os pontos aqui debatidos. Na primeira seção, elucidamos as concepções e princípios que embasam a formação docente inicial na IES-alvo e discutimos aspectos da parceria colaborativa como metodologia fundamental para que a formação inicial dos licenciandos em Letras ocorra de forma situada.

A seguir, apresentamos a proposta do núcleo de Letras na primeira edição do PRP, já finalizada. Discorremos sobre a conjuntura vivida diante do ineditismo do programa e os caminhos tomados para o desenvolvimento de atividades que forneceram aos licenciandos o pensar inicial sobre a construção de suas identidades docentes.

Na última parte, destinamos espaço à apresentação da proposta da segunda edição, em execução, do núcleo de Letras no PRP e às nossas considerações sobre as contribuições do PRP para a formação de futuros 
professores de línguas no contexto investigado. Para além de sublinharmos determinadas questões teórico-metodológicas que sustentam as atividades previstas, destacamos como temos enfrentado os desafios impostos pela pandemia, voltando-nos à realização de estágios remotos, os quais, a princípio, nos parecem estar oferecendo subsídios significativos para o desenvolvimento do pensamento crítico e reflexivo de todos os agentes envolvidos.

\section{Concepções sobre a formação docente do curso de Letras}

Em nosso contexto de formação de futuros professores de línguas, consideramos a escola pública como lócus de formação e temos desenvolvido projetos e ações no curso de Letras que aproximam os futuros professores dos professores em exercício e de tudo aquilo que ocorre nas escolas, para que possam vivenciar situações relacionadas com o "exercício da profissão" (NÓVOA, 2009), buscando articular teoria e prática a partir das 4 ações sugeridas pelo referido autor:

Em primeiro lugar, a referência sistemática a casos concretos, e o desejo de encontrar soluções que permitam resolvê-los. Estes casos são "práticos", mas só podem ser resolvidos através de uma análise que, partindo deles, mobiliza conhecimentos teóricos (...). Em segundo lugar, a importância de um conhecimento que vai para além da "teoria" e da "prática" e que reflecte sobre o processo histórico da sua constituição, as explicações que prevaleceram e as que foram abandonadas, o papel de certos indivíduos e de certos contextos, as dúvidas que persistem, as hipóteses alternativas, etc. (...) Em terceiro lugar, a procura de um conhecimento pertinente, que não é uma mera aplicação prática de uma qualquer teoria, mas que exige sempre um esforço de reelaboração (...). Em quarto lugar, a importância de conceber a formação de professores num contexto de responsabilidade profissional, sugerindo uma atenção constante à necessidade de mudanças nas rotinas de trabalho, pessoais, colectivas ou organizacionais. (NÓVOA, 2009, p. 34-35).

Nesse sentido, temos investido na última década por uma formação de professores a partir da metodologia da "parceria colaborativa" (FOERSTE, 2004), em que os futuros professores desenvolvem, sob a orientação do docente da universidade e supervisão de um professor experiente na escola, seus conhecimentos construídos na teoria, ao mesmo tempo que os próprios docentes e professores em exercício refletem sobre suas práticas e atualizam seus conhecimentos.

Essa metodologia de trabalho foi inicialmente implementada em nosso contexto em 2010, com a adesão do curso de Letras ao PIBID e, desde então, tem sido também a perspectiva de formação de professores nos estágios supervisionados do curso e, mais recentemente, a partir de 2018, dos subprojetos de Letras desenvolvidos no PRP institucional.

Ao historicizar sobre a parceria no campo educacional, Foerste $(2004$, p. 1) aponta que foi apenas no final do século XX que foi difundida a visão sobre a "parceria enquanto política pública na formação de profissionais de ensino". Segundo o autor:

Até os anos 80 esse trabalho integrado resultava de iniciativas e esforços individuais, geralmente centradas na boa vontade e compromisso de professores de algumas disciplinas do currículo dos cursos de licenciatura e algumas escolas. Raramente a relação estabelecida obedecia a acordos interinstitucionais, com regras negociadas, construídas a partir de reflexões coletivas sobre a prática docente (nas escolas e na universidade). Nessa parceria predominavam pressupostos teórico-práticos que acabavam sobrepondo o saber acadêmico aos saberes práticos dos profissionais do ensino básico. (FOERSTE, 2004, p. 3). 
A proposta de formação de professores que temos tentado construir com as escolas, por meio da parceria colaborativa na perspectiva de Foerste (2004), considera que a responsabilidade pela formação dos professores é papel também das escolas públicas e, nesse sentido, a negociação de objetivos leva em conta as especificidades dos contextos e o diálogo como fundamentais para o processo de construção individual e coletiva das identidades docentes (MARCELO, 2009).

A partir das tomadas de decisão e das práticas desenvolvidas, são mobilizados conhecimentos e saberes em uma atitude investigativa que valoriza e reconhece o professor em exercício nas escolas como coformador de futuros professores. Nessa dinâmica, ocorrem imprevistos, incertezas e desafios que reposicionam "a instituição escolar como um espaço indispensável para uma integração efetiva entre e a teoria e prática nos cursos de formação inicial" (FOERSTE, 2004, p. 8).

Nessa interação entre docente da universidade-estagiário-professor da educação básica, são problematizados aspectos metodológicos, políticos, éticos e culturais envolvidos com a docência e que contribuem para melhores compreensões sobre a complexidade envolvida na profissão (PIMENTA; LIMA, 2004), de forma contextualizada e situada sócio-historicamente.

Dessa forma, é pela articulação entre teorias e práticas que tem ocorrido a formação inicial de futuros professores de línguas no referido curso, com ações e reflexões que envolvem a mobilização de saberes sobre a estrutura e usos das línguas e sua relação com demais linguagens, considerando as práticas linguísticas como práticas sociais e, portanto, atribuindo ao professor de línguas um importante papel social ao desempenhar sua atividade profissional agente transformador, capaz de contribuir com mudanças na sociedade (GIROUX, 2000).

Tais princípios que embasam a formação inicial buscam responder às demandas dos diferentes sistemas de ensino público brasileiros, aproximando os futuros professores da realidade do "chão da escola", em um movimento crítico e reflexivo sobre a prática, partindo do pressuposto de Sacristán (2017) de que:

Não se pode descobrir a realidade do que ocorre no ensino senão na própria interação de todos os elementos que intervêm nessa prática. Se os professores têm de planejá-la, conduzi-la e reorientá-la, sua competência está em saber se desempenhar em situações complexas, embora uma determinada rotinização do comportamento profissional simplifique tudo isso, de modo que o que parece complexo e dificilmente governável desde esquemas conscientes de atuação profissional se torna fácil e quase automático ou "rotineiro' para o professor socializado profissionalmente. (SACRISTÁN, 2017, p. 204).

Afirmamos, portanto, que em nosso curso a inserção dos licenciandos nas escolas na perspectiva formativa da parceria colaborativa (FOERSTE, 2004), com a participação de professores da educação básica como coformadores desses futuros professores de línguas, tem sido melhor consolidada sobretudo a partir do programa institucional de formação docente PRP. Isso significa dizer que, embora essa parceria já fosse peça-chave na realização das disciplinas de estágio de língua materna e de línguas estrangeiras no curso em questão, com o advento do PRP, essa metodologia ganhou ainda mais força, pois as relações entre docentes da universidade e professores da educação básicatornaram-se mais estreitas e fortalecidas com a institucionalização que o PRP instaurou, potencializando a construção compartilhada de conhecimentos com os licenciandos.

Para avaliarmos as contribuições do PRP ao contexto investigado, apresentaremos as propostas dos subprojetos do curso de Letras da instituição em sua primeira (2018) e segunda edições (2020). 


\section{PRP/Letras: primeira edição (2018 a 2020)}

Antes de nos atermos à execução do projeto, cabe refletirmos sobre como aconteceu a implantação do PRP na instituição, num contexto de insegurança quanto à implementação do programa pelas instituições, haja vista o ineditismo da proposta, e de impasses sobre a origem do programa enquanto política de poder público.

Algo marcante no processo de proposição do projeto institucional foi a tarefa de se chegar a um conjunto de docentes que defendesse o engajamento institucional ao programa, visto que, por razões políticas, uma ampla parcela docente não enxergava no PRP uma oportunidade de refletir sobre a formação inicial no contexto do estágio supervisionado, mas sim uma proposta com fins partidários, sem partilha ideológica com preceitos advindos do programa PIBID, já amplamente reconhecido e defendido como lugar de reflexão sobre a práxis na formação docente inicial.

Essa negação do PRP foi observada em âmbito nacional, como pode ser comprovado tanto pelo número menor de instituições que submeteram projetos para o programa PRP (242 instituições no Edital PRP/ 2018, frente a 285 instituições no Edital PIBID/ 2018), quanto pelo menor número de cotas aprovadas para o PRP dentre as instituições que submeteram propostas em ambos os programas (240 cotas aprovadas para o Edital PRP/ 2018 da referida instituição, frente a 316 cotas aprovadas para o Edital PIBID/2018)2.

Alegações à parte, a proposta do PRP foi submetida com oito núcleos, entre eles, dois ligados ao curso de Letras: núcleo Língua Inglesa e núcleo Língua Espanhola, que, após redimensionamento do projeto institucional, por designação da CAPES, se restringiram a um só núcleo, que concentrou licenciandos (residentes) em três escolas da rede pública de uma cidade do interior paulista. Em consonância com o projeto institucional, o subprojeto tinha como objetivo geral dar visibilidade aos estágios supervisionados já em desenvolvimento na instituição, de maneira a promover a compreensão dos aspectos envolvidos no ensino e na aprendizagem de línguas nas escolas públicas, bem como a compreensão da complexidade envolvida na profissão docente (PIMENTA; LIMA, 2004), levando em consideração os conceitos de "parceria colaborativa" (FOERSTE, 2004) e de "identidades docentes" (FARIA; SOUZA, 2011).

Logo no início do PRP, já compreendemos os desafios que viriam e as razões da forte resistência institucional em aprovar o programa, já que a complexidade assentada no momento por que passavam as políticas educacionais, bem como a complexidade envolvida na relação universidade-escola se evidenciaram quando escolhemos participar do debate enquanto sujeitos integrados ao processo de construção de um programa que acabara de sair do papel.

Nesse contexto, a grande contribuição do PRP foi favorecer a interação dos licenciandos com a comunidade externa e interna à escola, uma vez que o acompanhamento e a participação das atividades de docência se estenderam durante três semestres letivos, levando-os a compreender a dimensão da docência em sua integralidade, abarcando a teoria, a prática e os diversos saberes da profissão docente (GAUTHIER et al., 1998; TARDIF, 2000).

Ademais, estando na linha de frente do exercício da profissão, os licenciandos chegaram a reflexões que revelaram os conflitos enfrentados pelo professor (preceptor) em diversos âmbitos, o que foi evidenciado nos relatórios finais de estágio, que deixaram transparecer as diferentes "vozes diretamente envolvidas no estágio supervisionado" (RODRIGUES, 2013), vozes essas que colocam os interesses do professor frente a frente com a legislação, com os que teorizam sobre o estágio e com os próprios estagiários, que representam 
a universidade na escola. Essas relações geralmente culminam em tensões nos momentos decisórios, uma vez que essas vozes podem defender interesses educacionais divergentes. Entretanto, todas essas tensões, além de fazerem parte do universo do profissional docente e contribuírem para a construção das identidades docentes, favorecendo a formação de profissionais mais preparados para os desafios da contemporaneidade, foram redimensionadas por meio de ações de crítica e reflexão desenvolvidas emparceria colaborativa durante todo o trabalho realizado.

No intuito de contribuir à formação dos licenciandos em Letras, o núcleo (i) desenvolveu ações de aprofundamento de reflexões sobre aspectos teóricos e metodológicos do estágio supervisionado; (ii) estudou temáticas relacionadas ao estágio compartilhado, uma vez que os pilares do projeto institucional eram os conceitos de colaboração e identidades docentes; (iii) possibilitou a vivência de "situações reais de ensino", tornando os licenciandos aptos a planejarem e avaliarem seus procedimentos didáticos de acordo com as reflexões teórico-metodológicas do campo do ensino de línguas; (iv) oportunizou articulação teórico-prática, instigando uma postura crítica e investigativa no que se refere aos conteúdos linguísticos, objeto do processo de ensino e de aprendizagem; (v) favoreceu a integração de recursos e tecnologias às práticas docentes, tornando os licenciandos aptos a estabelecerem relações entre diferentes linguagens e manifestações artísticas; (vi) encorajou a valorização do profissional docente, situando os professores como agentes de transformação educacional, fortalecendo nos licenciandos uma atitude afirmativa de ética e respeito com relação a contextos e situações interculturais e de diferenças.

Todos esses aspectos, que compuseram os objetivos do subgrupo Letras do PRP, foram trabalhados sob a perspectiva de três eixos principais de desenvolvimento e construção da parceria colaborativa, consonantes com o projeto institucional, quais foram: (i) identificação da escola e de seu entorno, momento em que os licenciandos compreendiam o contexto em que a escola se encontrava e refletiam sobre o impacto que a comunidade externa à escola opera nos processos educativos; (ii) imersão na escola, momento em que os licenciandos vivenciaram a docência em sua dimensão integral, incluindo as práticas educativas e o papel político do educador; e (iii) articulação entre teoria e prática, presente desde o início do estágio, permeando todas as etapas, favorecendo a práxis.

Esses eixos se distribuíram nas disciplinas de estágio supervisionado de modo a garantir que os licenciandos, representando a figura da universidade no contexto de estágio compartilhado, não fossem apenas observadores externos da escola, mas que se sentissem integrados à escola e capazes de construir, colaborativamente, a "realidade de ensino desejada".

Tendo a escola pública como lócus privilegiado, em conformidade com os princípios norteadores do curso de Letras, como sinalizado anteriormente, e vivenciando um contexto sem pandemia, em que o estágio foi realizado na modalidade presencial em sua integralidade, aos licenciandos foi oportunizada interação com diferentes realidades da escola de educação básica, visto que eles se distribuíram entre três escolas da rede pública que atendiam públicos diferenciados, entre Ensino Médio, Ensino Fundamental e Ensino Técnico, e compartilharam das experiências de todos os grupos nos momentos de partilha em nossas aulas, de modo a refletir conjuntamente sobre cada vivência de estágio, construída colaborativamente.

Além disso, os licenciandos tiveram a chance de conhecer e analisar, a partir das práticas vivenciadas junto com os professores e a partir da articulação teórico-prática proposta no PRP, as abordagens de ensino e de aprendizagem de línguas nesses três contextos, sendo capazes de reconhecer suas concepções epistemológicas subjacentes. Ademais, a heterogeneidade de estruturas físicas das escolas, de metodologias de 
ensino, de uso dos espaços educativos, de recursos usados nas aulas, de planejamento para a elaboração de planos de aula, do público-alvo atendido pelos diferentes contextos, dentre outros aspectos, ofereceu aos licenciandos um panorama abrangente das práticas possíveis em cada contexto, bem como dos desafios enfrentados pelo professor em cada realidade.

Essa imersão nas escolas culminou no desenvolvimento de propostas de ação desenvolvidas em parceria com os professores, de modo a propiciar aos licenciandos o conhecimento dos fazeres da profissão docente desde o planejamento, passando pela elaboração e execução de atividades de ensino diversas.

Refletindo sobre essas ações ocorridas no estágio compartilhado, vimos que os momentos de partilha de experiências de todos os sujeitos envolvidos na parceria eram sempre profícuos. Nesse tocante, foram oportunizadas reuniões periódicas com os licenciandos e com os professores preceptores, em formato de roda de conversa, para alinhamento de plano de atuação por parte de cada grupo atuante em cada escola, tomando como base as demandas de cada contexto e o diálogo com preceptores e com a gestão de cada escola envolvida, primando pela natureza colaborativa de nossa participação no estágio e compreendendo a dimensão da docência como um todo, no caminho para a construção de identidades docentes.

Além dessa ação de partilha, outra atividade proposta pelo projeto institucional, que propiciou momentos de interação entre orientadores de estágio e preceptores, foi a oferta de um curso de formação para os preceptores, oferecido na instituição como um curso de extensão, para o qual os professores orientadores de estágio junto ao PRP também foram convidados, e que teve como prioridade mostrar o alinhamento da universidade com as expectativas das redes de ensino públicas e conhecer as expectativas dos professores preceptores quanto à parceria com a universidade, favorecendo a caracterização do estágio supervisionado e compartilhado.

Cumpre salientarmos que o que se construiu de forma colaborativa no período em que se realizou o estágio supervisionado gerou impacto, inclusive, em propostas de mudança para o currículo do curso, que poderão ser levadas à execução durante o processo de reformulação por que passa o curso de Letras da referida instituição: os licenciandos enxergaram na oportunidade de estar no "chão da escola" por mais tempo e, pensando também no PIBID, desde o início do curso, uma saída para aumentar a confiança do professor recém-formado e diminuir o número de exonerações de cargos de professores da educação básica. Essa reflexão foi levantada quando comparado o êxito das ações de estágio dos residentes que já haviam sido pibidianos com outros que tiveram no estágio seu primeiro contato com a escola.

Para os licenciandos, quanto mais tempo em estágio, maior é a compreensão da dimensão docente, e, quanto mais cedo se interage com a comunidade escolar, maior é a chance de se construir identidades docentes antes da saída para o mercado de trabalho, preparando-se melhor para as adversidades da profissão.

Em suma, as contribuições do PRP na formação inicial vão ao encontro da valorização identitária e profissional dos professores, estimulando a autonomia dos licenciandos no enfrentamento dos desafios educacionais, a partir de práticas colaborativas.

\section{PRP/Letras: edição atual (2020 a 2022)}

Tendo o primeiro ciclo do PRP garantido um aprendizado consideravelmente fecundo aos estagiários (residentes), aos professores da educação básica (preceptores) e aos docentes de nossa IES (professores 
orientadores), em especial no cenário de nosso curso, houve grande interesse por parte de todos na continuidade das ações relacionadas ao programa, em busca do fortalecimento e da consolidação, cada vez maiores, do trabalho de formação de professores desenvolvido em nosso contexto, pautado sobretudo na parceria colaborativa, como já dito.

Desse modo, em consonância a algumas novas exigências do Edital PRP/2020, a nossa IES, no início de 2020, submeteu um novo projeto institucional, com a participação de cinco áreas prioritárias e uma área geral ${ }^{3}$. Nesse novo projeto, aprovado pela CAPES, preservou-se muito daquilo que já constava no projeto anterior - tais como a estrutura geral do programa; a vinculação do PRP com as disciplinas de estágio; o objetivo geral de dar projeção aos trabalhos que já vinham sendo desenvolvidos nas disciplinas de estágio da IES; o propósito de contribuir com a implementação de ações que estimulem ainda mais a articulação entre teorias e práticas, em colaboração com as escolas-parceiras envolvidas; dentre outros aspectos. Atualmente, o PRP conta com onze núcleos, dentre os quais se encontra o de Letras, referente à área prioritária de Língua Portuguesa, que tem as suas atividades distribuídas em três escolas públicas do interior paulista.

Uma das alterações feitas, no entanto, no âmbito do projeto institucional e que reverberou nos subprojetos, inclusive no de Letras, referiu-se aos pilares do programa: manteve-se a "parceria colaborativa" (FOERSTE, 2004), já conjecturada, e, ao seu lado, foi acrescentado o conceito de "práticas docentes" (CRUZ, 2007; FRANCO; GILBERTO, 2011; FRANCO, 2012).

Assim como Cruz (2007, p. 197), compreendemos que "a prática docente no contexto da sala de aula não pode ser encarada como um exercício meramente técnico, marcado pelo atendimento às prescrições curriculares desenvolvidas por outrem". Nessa mesma direção, Franco e Gilberto (2011, p. 2018) destacam o seguinte:

\begin{abstract}
Os tempos mudaram, os alunos apresentam um novo perfil e a compreensão do fazer pedagógico está exigindo reflexão sobre novas perspectivas para a prática docente. A práxis coloca-se como uma perspectiva de uma ação que cria novos sentidos para a prática docente, agindo contrariamente às ações mecânicas e/ou espontâneas do sujeito, posto que exige reflexão do coletivo, explicitação das intencionalidades, abertura para novas interpretações. A práxis como exercício pedagógico permite ao sujeito, enquanto sujeito histórico e coletivo, acessar os caminhos de sua autonomia.
\end{abstract}

As iniciativas da versão atual do PRP/Letras, então, ainda dentro daqueles três eixos mencionados (a identificação da escola e o seu entorno, a imersão na escola e a articulação entre teoria e prática), foram pensadas para que as práticas docentes fossem compartilhadas e situadas sócio-historicamente. Em resumo, o período de estágio deve constituir espaço e tempo, individuais e coletivos, relevantes no processo formativo do futuro professor, proporcionando-lhe a construção de saberes teóricos e práticos e, também, reflexões sobre as relações existentes na esfera escolar (PIMENTA; LIMA, 2004).

Isto posto, temos debatido a formação pedagógico-didática dos licenciandos e os conteúdos que suas práticas deverão contemplar. No caso, nas aulas de línguas - aqui, com foco nas aulas de Língua Portuguesa -, práticas que enfatizem as nuanças formais, funcionais, cognitivas e sociais dessas línguas.

No subprojeto desta edição, previmos a criação de projetos de ensino e atividades inovadores que se pautassem na perspectiva dialógica da linguagem, na visão heterogênea de língua e no estudo dos mais variados gêneros textuais/discursivos, sobretudo os digitais, já que a Base Nacional Comum Curricular (BNCC) avança justamente em relação à cultura digital (BRASIL, 2017, 2018). A BNCC reforça, na área de linguagens, em 
particular por conta do uso das tecnologias na contemporaneidade, a necessidade de serem trabalhados textos multimodais e questões de multiculturalismo (ROJO, 2012), por meio de atividades que contemplem a leitura, a produção de textos, a oralidade e a análise linguística/semiótica.

Vale destacarmos que o núcleo de Letras do PRP em questão tem buscado compreender, de forma crítica e problematizadora, a relação entre a BNCC e as reformulações curriculares em implementação nas escolas. Nesse movimento, são várias as aprendizagens da docência, dentre elas a importância do papel dos professores como profissionais intelectuais e agentes de transformação de suas práticas (GIROUX, 2001), não apenas meros executores de políticas educacionais que desconsideram a cultura local, as condições de trabalho docente e as concepções sobre ensino e aprendizagem.

Baseando-nos nas questões teórico-metodológicas anteriormente mencionadas, propusemos, portanto, algo que pudesse, para além de viabilizar aos licenciandos uma visão humanística e crítica sobre o papel e o impacto de sua futura atuação profissional na sociedade, conscientizá-los criticamente quanto às diferentes possibilidades de ensino de Língua Portuguesa. Nesse sentido, em um momento de pandemia em que houve grande ênfase na oferta de "conteúdos" aos alunos, foi objeto de problematização crítica constante a abordagem dos conteúdos linguísticos a partir de um normativismo crítico e racional, que, ao mesmo tempo que destaca a importância e utilidade da norma-padrão como elemento de autorregulação do sistema, respeita a diversidade linguística, as identidades e as atitudes que correspondem a essa variabilidade.

Em um contexto regular, na modalidade presencial, já teríamos tido desafios a serem superados para a concretização da proposta, com o objetivo de que licenciandos, professores da escola e da universidade, perante um trabalho colaborativo, fossem os responsáveis pelo "pensar" e pelo "fazer" o ensino. Nesse panorama, ainda surgiram a pandemia da Covid-19 e, consequentemente, a necessidade do "ensino remoto e emergencial" durante o indispensável isolamento social.

A partir disso, com a realização de estágios remotos, assim como sugere Liberali (2020) ao mencionar a expressão "inédito viável", utilizada por Paulo Freire (1987, 1992), buscamos criar condições para que o futuro fosse (re)construído. Segundo a autora,

Em nosso tempo, nunca foi tão mandatório pensar em possibilidades para ir além daquilo que conhecemos, daquilo que já vivemos, daquilo que pode ser repetido sem reflexão. A situação que vivemos exige que nos coloquemos frente ao contexto com nossa história como ferramenta para criar o possível. (LIBERALI, 2020, p. 14, grifos nossos)

Colocarmo-nos frente ao contexto com nossa história como ferramenta para criar o possível, como destacado na citação, significou mantermos a parceria colaborativa com as escolas públicas e com os professores da educação básica, apoiando-nos no ensino remoto emergencial no qual, às pressas, todos estiveram imersos.

Além disso, enxergamos nos estágios remotos uma rendosa oportunidade de os licenciandos compreenderem o que as escolas têm, de fato, enfrentado nos últimos meses e o que elas poderão esperar do futuro - que provavelmente não voltará a ser como antes. Como bem sinaliza Freitas (2020, s/p, online),

(...) toda experiência que a escola tem em relação à educação e à formação da infância e da juventude, ela tem que ser partilhada pelos estudantes que se formam professores. Toda a experiência, todas as vivências. (...) Esse [acompanhar o professor que está com atividades remotasdurante a pandemia] é um aprendizado interessante. Por quê? Mesmo que esse estudante esteja no último 
ano, por exemplo, e se forme, essa experiência ele leva para o trabalho dele, uma vez professor. E já dizem que a gente enfrentará certamente, futuramente, e essa geração mais ainda do que nós, (...), muitas outras pandemias, muitas outras situações talvez não tão graves como essa ou até piores do que essa. (...) Então o quanto mais nós pudermos entrar no trabalho do professor, no que significa esse esforço dele com todas as dimensões - emocional, o medo, a tristeza -, enfim, todas as sensações, os sentimentos do professor nesse momento fazem parte do que o constituem também, [fazem parte] da sua identidade profissional. E, portanto, o estagiário tem que viver isso também. Não só porque ele está vivendo uma pandemia como estudante, mas, ele se formando professor, ele tem que passar por entender também o que significou, o que vai significar para essas crianças esse momento do ensino remoto, esse distanciamento do contato com os professores, e o que significará o retorno à atividade e às aulas, que está aí em discussão acalorada. ${ }^{4}$

No quadro abaixo, apontamos as atividades que os estagiários têm desenvolvido até o presente momento.

\section{Quadro 1. Relação das atividades desenvolvidas nos estágios remotos do curso de Letras}

\section{ATIVIDADES REMOTAS}

- Participação em reuniões de planejamento com o professor da escola (e com a Coordenação Pedagógica e/ou Direção) para levantamento de dados sobre o contexto a ser vivenciado (perfil dos alunos, atividades remotas desenvolvidas, demandas etc.);

- Elaboração de materiais digitais e/ou atividades online e/ou jogos online sobre conteúdos indicados pelo professor;

- Acompanhamento e/ou auxílio ao professor na mediação de atividades online;

- Auxílio ao professor na correção de atividades dos alunos;

- Apoio online aos alunos para resolução de dúvidas/monitoria;

- Regências online com o acompanhamento do professor; e

· Participação em outras atividades online propostas pelo professor.

Fonte: própria

Se, por um lado, a realização dos estágios remotos tem nos mostrado que nada substitui a presença física do estagiário na escola, onde há a oportunidade de ele ter um contato mais pessoal e próximo com alunos, professores e demais profissionais, estimulando a construção de suas identidades docentes, constituídas com as interações com os diversos contextos da escola-campo; por outro, essa nova configuração de estágio (i) tem mantido assíduas as trocas de conhecimentos entre preceptores, licenciandos e professor orientador, que parecem estar mais próximos, embora mediados por diferentesferramentas digitais -WhatsApp, e-mail, AVAs, etc. -, e (ii) tem estimulado o engajamento e a autonomia dos residentes, os quais, com postura ativa, têm visto a sua participação no estágio como um espaço de interação, de letramentos e de pesquisa.

Por último, consideramos que as experiências já ocorridas neste período de estágio remoto também podem fornecer dados para o processo de reformulação pelo qual passa o presente curso de Letras, no sentido de que, na formação de nossos alunos, está mais do que na hora de as imbricações entre tecnologias e ensino de línguas avançarem, tornando-se um tópico debatido de forma ampla nas disciplinas e possibilitando a esses licenciandos, em suas práticas, um domínio suficiente para utilizarem os recursos tecnológicos pedagógica e criticamente. 


\section{Considerações finais}

Ao longo deste artigo, trouxemos apontamentos condizentes com uma perspectiva de formação de professores crítica e sócio-historicamente contextualizada, viável pela interação universidade-escola, que impulsiona professores em formação inicial e professores em exercício a planejarem, executarem e refletirem sobre as suas práticas, considerando o contexto escolar no qual estão imersos.

Buscamos, de forma objetiva, elencar as contribuições dos estágios supervisionados e, por conseguinte, do PRP a licenciandos em Letras de uma dada IES, considerando-os espaços fundamentais para que os professores de línguas iniciem a sua emancipação, desprendendo-se de uma atitude mais passiva e expectante diante das situações escolares vivenciadas, rumo a uma postura mais independente, em que estejam cientes de que as suas tomadas de decisão repercutem política, cultural e socialmente. Concordamos com Giroux (2000) quando afirma que:

(...) Nem o conhecimento que os professores ensinam, nem as maneiras empregadas para ensinar são inocentes; ambos estão informados por valores que precisam ser reconhecidos e usados criticamente por suas implicações e efeitos. Dito de outra maneira: os educadores e as educadoras têm que manifestar seu próprio envolvimento subjetivo em relação ao conhecimento e às práticas que usam na sala de aula. Discussões explícitas do que, de como e por que ensinamos e aprendemos são necessárias para transformar nossos próprios investimentos políticos, culturais e ideológicos em recursos que façam com que a autoridade seja o objetivo da autocrítica como uma aplicação da crítica social. (GIROUX, 2000, p.72)

Os movimentos empreendidos que levam os professores em formação inicial e em exercício a desenvolverem reflexões crítico-reflexivas e a reafirmarem suas posições políticas, culturais e ideológicas em atos de resistência, sabendo fazer-se presente no contexto profissional das escolas, evidenciam a importância de um programa como o PRP para a consolidação de parcerias entre universidades e escolas, antes, durante e após a pandemia.

Assim, a grande contribuição do PRP para o contexto pesquisado tem sido viabilizar a implementação da parceria colaborativa como metodologia fundamental para que, na formação inicial dos licenciandos em Letras, eles tenham as experiências mais fidedignas possíveis às realidades escolares que encontrarão após estarem licenciados. Como já mencionado, na IES-alvo, o PRP oportuniza a ampliação da carga horária de imersão do licenciando no contexto escolar; e, para além disso, permite-lhe desenvolver as ações em consonância com uma proposta maior, a do subprojeto do núcleo de Letras, o que qualifica ainda mais as discussões ao longo do seu período de estágio, visto que todo o grupo está envolvido com e debatendo as mesmas frentes de trabalho.

Neste momento histórico, em que vivemos uma pandemia com sérias consequências econômicas e educacionais para o país, a opção pela realização dos estágios na modalidade remota foi possível graças à estrutura institucionalizadado PRP e justifica-se pela importância da inserção desses futuros professores na realidade das escolas como elas se configuram (e não como imaginamos ou gostaríamos que se configurassem), na perspectiva de uma formação docente crítica defendida por Zeichner (2008), segundo o qual:

O propósito de se trabalhar para a justiça social é uma parte fundamental do ofício dos formadores de educadores em sociedades democráticas e não deveríamos aceitar outra coisa, a não ser algo que nos ajude a progredir em direção a essa realização. (ZEICHNER, 2008, p.548). 
Enquanto instituição de ensino que defende e pratica a formação de professores por meio da parceria colaborativa (FOERSTE, 2004) com as escolas, nos consideramos no dever de responder às demandas que nos são colocadas pela sociedade e, neste momento, estar junto às escolas e aos professores da educação básica é uma oportunidade ímpar para podermos acompanhar e aprender de que forma as teorias e práticas pedagógicas se implementam na modalidade remota, contribuindo para a constituição de nossas identidades e práticas docentes.

Nesse sentido, tanto a estrutura e parceria com as redes de ensino propiciadas pelo PRP quanto as ações nas escolas possibilitam compreensões mais situadas sócio-historicamente sobre as demandas de alunos e professores, muitas vezes silenciadas e apagadas no contexto presencial, favorecendo uma visão mais crítica sobre o "chão da escola", o que nos parece fundamental para o enfrentamento dos desafios impostos atualmente aos sistemas públicos de ensino no Brasil.

AGRADECIMENTOS: CAPES. 


\section{Endnotes}

1 Para informações desse programa, consulte <https://capes.gov.br/educacao-basica/capespibid $>$. Acesso em: 13 set. 2020.

2 Esses números são encontrados no site da CAPES, nas divulgações do resultado final e do número de cotas aprovadas em cada instituição. Os dados estão disponíveis em: <https://capes.gov.br/educacao-basica/ programa-residencia-pedagogica> e <https://capes.gov.br/educacao-basica/capespibid/editais-e-selecoes $>$. Acesso em: 13 set. 2020.

3 De acordo com o Edital PRP/2020, são áreas prioritárias Alfabetização, Biologia, Ciências, Física, Língua Portuguesa, Matemática e Química; e, áreas gerais, Arte, Educação Física, Filosofia, Geografia, História, Informática, Língua Inglesa, Língua Espanhola, Sociologia, Intercultural Indígena, Educação do Campo e Pedagogia.

4 Trecho de fala transcrito da participação de Freitas na mesa intitulada "A construção histórica do Estágio Supervisionado no movimento de defesa da qualidade na formação dos profissionais da educação", ocorrida durante a transmissão online do IV Encontro de Estágio Supervisionado (FAED/UFPA), no dia 01 de setembro de 2020. Disponível em: <https://www.youtube.com/watch?v=0oMZZqqYdBk>. Acesso em: 25 set. 2020.

\section{REFERÊNCIAS}

BRASIL. Ministério da Educação. Base Nacional Comum Curricular. Educação é a base. Ensino Médio. Brasília: MEC/CONSED/UNDIME, 2018. Disponível em: <http://basenacionalcomum.mec.gov.br/wp-content/ uploads/2018/04/BNCC_EnsinoMedio_embaixa_site.pdf>. Acesso em: 31 out. 2018.

BRASIL. Ministério da Educação. Base Nacional Comum Curricular. Educação é a base. Brasília: MEC/CONSED/ UNDIME, 2017. Disponível em: <http://basenacionalcomum.mec.gov.br/wp-content/uploads/2018/02/bncc-20dez-site.pdf>. Acesso em: 28 ago. 2018.

CAPES. O Programa de Residência Pedagógica. Disponível em: <https://capes.gov.br/educacao-basica/ programa-residencia-pedagogica>. Acesso em: 13 set. 2020.

CRUZ, G. B. da. A prática docente no contexto da sala de aula frente às reformas curriculares. Educar em Revista, Curitiba, n. 29, p. 191-205, 2007. Disponível em: <https://www.scielo.br/pdf/er/n29/13.pdf>. Acesso em: 14 dez. 2019.

FARIA, E. de; SOUZA, V. L. T. de. Sobre o conceito de identidade: apropriações em estudos sobre formação de professores.Psicol. Esc. Educ., v. 15, n. 1, p. 35-42, 2011. Disponível em: <https://www.scielo.br/pdf/pee/ v15n1/04.pdf>. Acesso em: 20 ago. 2017.

FRANCO, M. A. R. S. Pedagogia e prática docente. São Paulo: Cortez, 2012. 
FRANCO, M. A. R. S.; GILBERTO, I. J. L. A prática docente e a construção de saberes pedagógicos. Revista Teias, Rio de Janeiro, v. 12, n. 25, p. 212-224, maio/ago. 2011. Disponível em: <https://www.e-publicacoes. uerj.br/index.php/revistateias/article/view/24177/17155>. Acesso em: 17 jan. 2019.

FOERSTE, E. Parceria na formação de professores. Revista Iberoamericana de Educación, v. 34, n. 3, p. 1-12, 31 dic. 2004. Disponível em: <https://rieoei.org/RIE/article/view/3547/4045>. Acesso em: 24 abr. 2009.

FREIRE, P. Pedagogia da Esperança: um reencontro com a Pedagogia do Oprimido. Rio de Janeiro: Paz e Terra, 1992.

FREIRE, P. Pedagogia do Oprimido. Rio de Janeiro: Paz e Terra, 1987.

GAUTHIER et al. Por uma teoria da Pedagogia: Pesquisas Contemporâneas sobre o saber docente. Ijuí: Unijuí, 1998.

GIROUX, H.A. Los profesores como intelectuales transformativos. Revista Docencia, v.15, 2001. p.60-66. Disponível em: <http://revistadocencia.cl/ revist37/web/images/ediciones/docencia_15.pdf>. Acesso em: 14dez. 2003.

GIROUX, H. A. Pedagogia crítica como projeto de profecia exemplar: cultura e política no novo milênio. In: IMBERNÓN, F. (Org.) A educação no século XXI: os desafios do futuro imediato. Porto Alegre: Artmed, 2000. p. 65-75.

IMBERNÓN, F. Formação docente e profissional: formar-se para a mudança e a incerteza. São Paulo, Cortez.

LIBERALI, F. C. Construir o inédito viável em meio a crise do coronavírus - lições que aprendemos, vivemos e propomos. In: LIBERALI, F. C. et al. (Orgs.). Educação em tempo de pandemia: brincando com um mundo possível. Campinas: Pontes Editores, 2020. p. 13-21.

MARCELO, C. A identidade docente: constantes e desafios. Form. Doc., Belo Horizonte, v. 01, n. 01, p. 109131, ago./dez. 2009. Disponível em: <https://revformacaodocente.com.br/index.php/rbpfp/article/view/8/6>. Acesso em: 25 maio 2010.

NÓVOA, A. Professores: imagens do futuro presente. Lisboa: Educa, 2009.

PIMENTA, S. G.; LIMA, M. S. L. Estágio e docência. São Paulo: Cortez, 2004.

RODRIGUES, M. A. Quatro diferentes visões sobre o estágio supervisionado. Revista Brasileira de Educação, Belo Horizonte, v. 18, n. 55, p. 5-24, out.-dez. 2013. Disponível em: <https://www.scielo.br/pdf/rbedu/ v18n55/11.pdf>. Acesso em: 18 nov. 2014.

ROJO, R. Pedagogia dos multiletramentos: diversidade cultural e de linguagens na escola. In: ROJO, R; MOURA, E. (Orgs.). Multiletramentos na escola. São Paulo: Parábola, 2012. p. 11-31. 
ROMANOWSKI, J. P.; MARTINS, P. L. O. Formação continuada: contribuições para o desenvolvimento profissional dos professores. Rev. Diálogo Educ., Curitiba, v. 10, n. 30, p. 285-300, maio/ago. 2010. Disponível em: <https://periodicos.pucpr.br/index.php/dialogoeducacional/article/view/2416/2332>. Acesso em: 10 jul. 2016.

SACRISTÁN, J.G. O currículo: uma reflexão sobre a prática. São Paulo: Penso editora, 2017.

SANTOS, O. J. Pedagogia dos conflitos sociais. Campinas, SP: Papirus, 1992.

SAVIANI, D. Formação de professores: aspectos históricos e teóricos do problema no contexto brasileiro. Revista Brasileira de Educação, Belo Horizonte, v. 14, n. 40, p. 143-155, jan./abr. 2009. Disponível em: <https://www.scielo.br/pdf/rbedu/v14n40/v14n40a12.pdf>. Acesso em: 12 jan. 2020.

TARDIF, M. Saberes docentes e formação profissional. Petrópolis: Vozes, 2002.

TARDIF, M. Saberes profissionais dos professores e conhecimentos universitários: elementos para uma epistemologia da prática profissional dos professores e suas conseqüências em relação à formação para o magistério. Revista Brasileira de Educação, Belo Horizonte, n. 13. p. 5-24, jan./fev./mar./abr. 2000. Disponível em: <http://anped.tempsite.ws/novo_portal/rbe/rbedigital/RBDE13/RBDE13_05_MAURICE_TARDIF.pdf>. Acesso em: 21 jan. 2001.

ZEICHNER, K.M. Uma análise crítica sobre a "reflexão" como conceito estruturante na formação docente. Educ. Soc., Campinas, vol. 29, n. 103, p. 535-554, maio/ago. 2008. Disponível em: <https://www.scielo.br/ pdf/es/v29n103/12.pdf>. Acesso em: 27 jan.2021.

BIAZOlli, C. C.; GREgolin, I. V.; STASSI-SÉ, J. C.; Contribuições do Programa Residência Pedagógica à Formação Inicial de Futuros Professores de Línguas: aspectos da parceria colaborativa Formação Docente - Revista Brasileira de Pesquisa sobre Formação de Professores. Belo Horizonte. Vol. 13, nº 26 (p. 155-170) 30 abr. 2021. ISSN:2176-4360. DOI https://doi.org/10.31639/rbpfp.v13i26.420 